\title{
Drug Use Predictors Identified in the School Environment
}

\author{
Witold Jedynak and Marek A. Motyka
}

\begin{abstract}
Drug use is commonplace amongst youths. Alongside the family environment, school is the second place which shapes children's opinions and attitudes. The aim of this research was to identify factors in the school environment conducive to the use of legal and illegal drugs as well as those which protect against such actions. In order to answer the formulated research questions a representative sociological survey was carried out within the Podkarpackie province in Poland on a sample of nearly 2,500 students from 27 secondary schools. A stratified random sampling respondents' selection method was applied. A questionnaire was used to collect data. Empirical data analysis showed the existence of interesting relationships between adolescents' school activities and engaging in risky behaviours. The results of this research may be used for prevention programmes.
\end{abstract}

Key words: youths, school environment, alcohol, illegal drugs, addiction prevention

Witold Jedynak, $\mathrm{PhD}$, is an Associate Professor and Director of the Institute of Sociology, Rzeszów University. $\mathrm{He}$ is an academic teacher and author/co-author of more than eighty publications on the sociology of religion, the sociology of morality, social and political ethics and history. Major publications include: "From philanthropy and charity to social work: Polish perspective". In Selected socio-psychological aspects of social work. Jedynak W., Kinal J., Lipczyński A., \& Rynkowska, D. (eds.). Rzeszów: University of Rzeszow 2016 and "Religious Education at Polish schools in the context of sociological studies". Humanities and Social Sciences, 2018, 4, 99-109.

Marek A. Motyka, PhD, is an Assistant Director of Education at the Institute of Sociology, Rzeszów University. He is an Assistant Professor, an academic teacher and author of social research among young people, author and co-author of several dozen publications on the risks associated with psychoactive substance use, addiction therapist. Major publications include: Socio-cultural determinants of drug addiction. The scale and causes of the phenomenon among youth of Podkarpackie province. Rzeszów: University of Rzeszow, 2018; "The smombie generation: characteristics and typology". Social Space, 2018, 1(15), 169-200 and "The Beneficial Effects of LSD for the Ultimate Quantum Machine: Conflicting Evidence-Based Inference from the Cyberspace and the Literature". Research and Advances in Psychiatry, 2019, 6(1), 25-35. Co-operation with Ahmed Al-Imam \& Salim Rasheed Al-Obaidi. 


\section{Introduction}

The school environment together with the family and peer environment are the main areas of functioning and activity for adolescents. Youths shape their attitudes, assimilate standards, and become a member or an outsider of a given community on the basis of behavioural patterns observed within these environments. The environments in question also play an important role in the process of maturing. Through observing, adopting and rejecting significant behaviours within their peer environments, individuals arrive at their own definitions (Bandura, 1977; Lee et al., 2004). The family environment should have a stabilising effect on discrepancies which children may encounter as a result of observing conflicting attitudes towards generally accepted standards (honesty, respect, diligence, respect for community property, etc.). Whereas education and learning take place in school, as it provides knowledge and teaches how to enter into social interactions (White, 2006).

The school environment is a place where emotional states are experienced, both those pleasant and expected, as well as painful and chronic. Ambivalent experiences stem both from contacts with peers whom the individual feels the need to associate with on account of the pleasant feelings which accompany these relationships as well as unpleasant tensions associated with functioning within a diverse group of peers. Awareness of continual learning progress assessment throughout the entire education process is also highly stressful (Walker, 2016).

The first contacts with illegal drugs seem to be a phenomenon which is observed more frequently in peer and family environments (Brook et al., 1990; Bahr et al., 2005; Barnard, 2005) than at educational establishments. However, on account of the substantial amount of time adolescents devote to all kinds of educational activities, the school environment may be used to observe drug use determinants associated with the school setting, their influence on attitudes towards legal and illegal drugs and decisions on the use thereof.

\section{Aim of the Research}

The aim of the research was to determine the scale of drug use amongst youth and to identify social and cultural determinants for using these in the region in question. In order to determine the scale and causes for drug use by youths, the following research problems have been formulated setting out research directions:

- What environmental determinants are conducive for more liberal youth attitudes towards drugs?

- What family determinants impact drug use decisions?

- What demographic factors impact youth drug use decisions?

- What cultural factors impact youth drug use decisions?

- What is the role of pop culture in creating a positive image for drugs? 
In order to find an answer, detailed questions were phrased, research hypotheses were formulated, and variables and indicators were identified. The paper presents correlations identified between variables associated with the school environment and attitudes towards legal and illegal drugs and use thereof. Answers to the following questions were sought during the empirical data analysis:

1. What is the relationship between the respondents age (year) and drug use?

2. What is the relationship between the indicated general feeling in a given class group and substance use declarations?

3. What is the relationship between commitment to the education process and drug use? The following have been adopted as education commitment indicators:

- $\quad$ student status (acc. to most frequently received grades);

- $\quad$ participation in extra-curricular activities (extracurricular clubs, language courses, etc.);

- $\quad$ plans for the future and educational aspirations;

- $\quad$ approach to school activities (truancy vs regular attendance).

\section{Material and Methods}

The presented data has been derived from empirical research carried out during the 2015-2016 academic year on a random sample of students from secondary schools in Poland's Podkarpackie province. Podkarpackie Voivodeship is in the south-eastern part of Poland. Some researchers consider this part of Poland as a region with a high rate of religiosity when compared to other Polish provinces and as a region with preserved traditional customs, per which interpersonal ties are of great prominence (Sadowski, 2013). Podkarpackie Provincial Superintendent of Education consented to the research ${ }^{1}$. Participation in the research was voluntary.

In order to obtain representative outcomes a stratified random sampling method was adopted: the research area was divided into three strata: schools in Rzeszów (provincial capital), schools in cities with populations of more than 20 thousand residents and schools from towns and villages with populations of up to 20 thousand residents. Random selection only applied to schools in the first stratum. Cities, towns and villages were randomly selected first in the second and third strata, followed by given schools. In total 27 schools were randomly selected (9 in each stratum). Students in one form from each year were surveyed in

\footnotetext{
${ }^{1}$ Consent of the Provincial Superintendent of Education for the implementation of surveys among high school students (No. ORE.031.161.2015 of 10/09/2015).
} 
the selected schools. Classes were selected for the research sample based on organisational capacities of given schools.

An original, self-administered survey questionnaire was used to collect data. The questionnaire comprised thirty-one questions on four pages (nineteen closed ended questions and twelve semi-open-ended questions were phrased in order to obtain answers to the research problems. Some of the questions aimed to determine the family situation, assess students' school achievements and their educational aspirations, determine out-of-school activities, ways of spending free time, hobbies and attitudes to certain values (love, freedom, family, faith, health, friendship, work, study). Demographic questions were also asked (about sex, age, residential address). Instructions with information on how to answer were printed next to the questions. Data collected from respondents was correlated in order to determine relationships between variables. A pilot was carried out in order to verify the research tool prior to carrying out research proper.

In all 103 randomly selected forms, the research was carried without a teacher in attendance. Through this process, respondents were to feel more comfortable. At the outset, students were informed that the research was anonymous and that participation was voluntary. No one refused to take part. After a short introduction, the researcher distributed questionnaires which were then collected once completed. Respondents were eager to take part and did not report any difficulties associated with completing the form.

In the end, data was collected from nearly 2,500 students from 103 forms in 27 schools. Following a review of the collected empirical data, 2,273 correctly completed questionnaires qualified for statistical analyses. All incomplete questionnaires were rejected. The research sample comprised $46 \%$ boys and $54 \%$ girls. The respondents were between 16 and 19 years old. Age in the research sample was distributed as follows: 16-year-old: 32\%, 17-year-old: 28\%, 18-year-old: 30\%, 19-year-old: $10 \%$. The vast majority of research participants $(64 \%)$ inhabited rural areas, the remaining 36\% were from towns and cities in the Podkarpackie province.

The data were entered into a SPSS Statistics 20 programme and then subjected to statistical analysis. The chi-square test was applied to determine the significance of relationships between variables whereas Phi, Cramér's V and Gamma coefficients were used to measure the correlation power. Statistical significance was assumed for $p \leq 0.001$.

The obtained results were compared with national research results and those from selected other countries.

\section{Results}

Taking into account the scale of drug use amongst Podkarpackie province secondary school youths, contacts with marijuana were indicated by $30 \%$ of students (675 individuals), use of other drugs was indicated by $9 \%$ (202 respondents), smoking tobacco - 23\% (511 students) and alcohol consumption by $65 \%$ (1468 individuals). Boys were more likely to drink alcohol (boys: 69\%; girls: 61\%) and use illegal drugs (boys: 38\%; girls: 26\%). Students 
residing in towns and villages showed similar results within the scope of alcohol consumption (town: 67\%, village: 63\%). Use of illegal drugs was more widespread amongst those residing in towns (38\%) than villages (28\%).

In the research in question, marijuana and other drugs were treated separately due to such a differentiation of these substances by the respondents. During the research tool pilot, most students were against including marijuana into the drug category and a decision was taken to split it. In the "other drugs" category, youths most frequently indicated the use of amphetamine, NPS, cocaine, LSD and extasy.

\section{The Respondents' Year (Grade)}

Thirty-two percent of the youths were in first classes, $29 \%$ were in second classes, the same percentage were on third classes and 10\% were in fourth classes. The collected empirical data indicated that as the respondents' class increases so do the figures for smoking cigarettes, alcohol drinking, smoking marijuana as well as using other drugs. Five percent of students of first class admit to using other drugs and this percentage increased almost three-fold in the oldest group of respondents (14\%). The table below shows a breakdown of responses pertaining to substance use in each of the years subject to the research.

Table 1: Use of Drugs in Classes

\begin{tabular}{|c|c|c|c|c|c|c|}
\hline \multicolumn{2}{|c|}{ Class } & First classes & Second classes & Third classes & Fourth classes & statistics \\
\hline & cigarettes & $17 \%$ & $21 \%$ & $26 \%$ & $35 \%$ & $\mathrm{p} \leq 0.001$; Cramér's V $=0.125$ \\
\cline { 2 - 7 } & alcohol & $41 \%$ & $60 \%$ & $86 \%$ & $92 \%$ & $\mathrm{p} \leq 0.001 ;$ Gamma $=0.488$ \\
\cline { 2 - 6 } & marijuana & $18 \%$ & $31 \%$ & $38 \%$ & $39 \%$ & $\mathrm{p} \leq 0.001$, Gamma $=0.270$ \\
\cline { 2 - 6 } & other drugs & $5 \%$ & $9 \%$ & $11 \%$ & $14 \%$ & $\mathrm{p} \leq 0.001 ;$ Gamma $=0.264$ \\
\hline
\end{tabular}

Source: Own research $(n=2273)$

The Gamma coefficient is highest for alcohol consumption results, pointing the biggest relationship between the selected variables. In the remaining categories, despite weak relationships, tobacco and marijuana smoking as well as use of other drugs are statistically significant and evidently increase with each subsequent year. 


\section{General Feeling in a Class}

Correct relations between students in the same class - where the following play an important role: mutual acceptance, respect and tolerance - can be decisive when it comes to positive general feelings of school interactions' participants, whereas experiencing rejection by peers may lead to engaging in risk behaviours (Véronneau et al., 2014). In order to determine whether drug use may be influenced by subjective feelings of youths experienced in relations with other students in the same class, the questionnaire included a question on how they feel in their class. Three answers ordering their subjective feelings were suggested to describe how they feel. During empirical data analysis, it was determined that $84 \%$ of students indicated "positive" general feelings in their class, $3 \%$ of respondents described it as "negative", with $13 \%$ unable to provide an unambiguous reply, opting for "neither good nor bad". These data were then compared with drug use figures.

In the group of respondents marking answers classified as "positive" - 30\% showed use of drugs, a similar percentage (33\%) indicated their using among students unable to provide an unambiguous answer ("neither good nor bad"). However, in the group of students who marked responses pointing to "negative" general feeling, 50\% admitted to using drugs. Nevertheless, an analysis of the collected empirical data did not show a statistically significant relationship between the indicated general feeling and drug use.

\section{Commitment to Education: Student Status}

Student status predominantly defined by students on the basis of received grades (in Poland, 1 is the lowest grade and 6 is the top grade) and may constitute one of the variables used for identifying drug use phenomenon determinants. Researchers confirm, that students who receive lower grades are more likely to use legal and illegal drugs than those who receive higher grades (Williams et al., 2007; Heradstveit et al., 2017).

Eighteen percent of research participants indicated that they receive "sixes and fives", 43\% deemed themselves to be predominantly "grade four" students, whereas $39 \%$ pointed that they receive "threes and lower grades". These data were then compared with drug use figures.

Smoking tobacco was indicated by $12 \%$ of the top-grade students, $16 \%$ of the "grade four" students and $35 \%$ of the "grade three" students admitted smoking cigarettes $(\mathrm{p} \leq 0.001$; Cramér's V $=0.241$ ). Analogously, $51 \%$ of the best grades' students indicated alcohol consumption, $60 \%$ of the "grade four" students and $76 \%$ of respondents receiving the lowest grades indicated alcohol consumption ( $\mathrm{p} \leq 0.001$; Cramér's $\mathrm{V}=0.224)$. On average, one in six $(16 \%)$ of the top-grade students admitted drug use, with one in four $(27 \%)$ in the "grade four" group and $43 \%$ of the lowest grade students admitting to using these substances. Statistical analysis indicated a relationship between the indicated student status and drug use: Chi-square $=114.125 ; \mathrm{p} \leq 0.001 ;$ Cramér's $\mathrm{V}=0.224$; The above data confirm that students achieving higher grades use cigarettes, alcohol and drugs significantly less frequently than 
students who achieve lower grades. It is highly probable that concentrating on studying and devoting time to education do not go hand in hand with drug use. At the same time, it may be presumed that using such substances is conducive to a reduction of time devoted to study and a deterioration of the ability to memorise resulting in worsening performance in terms of learning. Here lower grades may be taken as confirmation of the above presumption.

\section{Commitment to Education: Participation in Extra-curricular Activities}

More than half of the sample (55\%) denied participation in extra-curricular activities and the remaining $45 \%$ show engagement in such activities. Private lessons, extracurricular clubs, exam study clubs, foreign language courses, computer literacy and IT courses and, dance lessons and sports practice, comprise the most frequently indicated activities. The responses were compared against drug use declarations. However, no statistically significant differences in terms of drug use figures were found between respondents who attend extra-curricular activities and those who do not: an average one in three research subjects from each group indicated drug use. Statistical analysis did not yield a relationship between participation in extra-curricular activates and use of these substances and thus, it may be presumed that amongst the youths in the sample, engaging in additional educational activities did not constitute a significant protective factor against drug use.

\section{Commitment to Education: Future Education Plans}

The research also aimed to identify the relationship between a declared intention to remain in education and drug use. One of the survey questions probed for respondents' plans within the scope of further education. Sixty-three percent of research participants indicated such aspirations, one in four $(26 \%)$ were unable to state their intentions within this scope and $11 \%$ indicated that they wish to end their education at the current stage. Data analysis identified drug use declarations disproportions amongst these groups. Amongst respondents confirming readiness to continuing education, on average one in four (26\%) admitted to using these substances. In the group of undecided students, 39\% indicated using drugs and the highest drug use proportion (45\%) was found amongst students who do not intend to pursue further education. Data analysis indicated a statistically significant relationship between the compared variables: Chi-Square $=56.113 ; \mathrm{p} \leq 0.001$; Cramér's V $=0.157$.

It is possible that for adolescents, educational aspirations constitute a protective factor against drug use. Refraining from using these substances, due to fear of experiencing possible intellectual deficiencies, may be an effective barrier protecting students against drug initiation. Awareness of potential losses, such as disqualification from the dream university course (people with a police drug possession "record" cannot apply to study law) may have protective benefits. 


\section{Commitment to Education: Intentional School Absence}

Another research aim was to identify a relationship between truancy and a liberal approach to drugs and their use. There were three answers for respondents to choose from to a question on intentional absences: "often", "rarely" and "I do not truant". Seven percent of students admitted to truanting often, every other respondent $(51 \%)$ stated they "rarely" do it and $42 \%$ of the respondents denied truanting. These results were compared with drug use declarations data.

Empirical material analysis demonstrated that the lowest drug use proportions (15\%) was amongst students who deny truanting. Amongst those who declare rare intentional absences, four in ten $(39 \%)$ declare using drugs, whereas amongst those who truant "often" more than three quarters (78\%) use drugs. Statistical analysis indicated a statistically significant relationship between the variables: Chi-Square $=305.154 ; \mathrm{p} \leq 0.001$; Cramér's $V=0.366$. The data shows that youths who play truant are likely to use drugs more frequently that youths who do not play truant. The value of Cramér's V coefficient allows one to ascertain that amongst the school environment drug use causes subject to research, truancy is a variable which influence using these substances to a greatest degree.

The etiology of drug use amongst truants may vary. Students who skip school lessons may do so due to family problems, conflicts with peers, under the influence of other people or because of fear of receiving a low grade (lack of preparation for lessons); certainly, more often due to experiencing powerful unpleasant emotional states than pleasant ones. Saying yes to drugs in such circumstances is much easier than when a student is not experiencing internal crises. Additionally, it may be much easier to decide to use drugs for individuals who have decided to intentionally skip school, as breaking one rule (obligatory school attendance) may be conducive to breaking other norms (engaging in socially unacceptable behaviours). It is also highly probable that in some cases, playing truant is a result of prior drug use. Individuals who use drugs play truant as they are subject to complex and diverse effects of intoxicants.

Drug initiation may also occur under the influence of alcohol consumed whilst truanting (Henry \& Thornberry, 2010; Dembo et al., 2014). Data pertaining to alcoholic beverage consumption by youths participating in the research compared with truancy responses showed that the highest proportion of alcohol consumption is reported by truants, regardless of truancy frequency (77\% out of the "rare" truants and 92\% out of "often" truants). Empirical data analysis indicated that there are differences in alcohol consumption prevalence between youths who do not play truant and those who do skip lessons: Chi-Square $=302.067$; $\mathrm{p} \leq 0.001$; Cramér's $\mathrm{V}=0.365$. Thus, consuming alcohol during intentional school absences may be conducive to drug use.

Additionally, more liberal stands towards drugs were observed amongst students who confirm intentional absences from school. Two variables were used in the presented study for the stands in question: 1) perception of drugs as safe substances and: 2) opinion on marijuana legalisation. 
Data analysis has shown that students who do not play truant are least likely to consider drugs to be safe (13\%) and are also least likely to be in favour of legalising marijuana (28\%). Stands towards these issues change together with increasing school absence; 24\% students who indicated truanting "rarely" and $45 \%$ which pointed truanting "often" consider drugs to be safe. Analogously, half of the respondents who showed "rare" truanting are in favour of legalising marijuana, whereas in the often-truant group it is as much as $70 \%$ of the students (Table 2).

Table 2: Frequency of Truancy/Attitude to Drugs

\begin{tabular}{|c|c|c|c|c|c|}
\hline \multicolumn{2}{|c|}{ Frequency of truancy } & $\begin{array}{c}\text { I do not } \\
\text { truant }\end{array}$ & I rarely truant & I often truant & Statistics \\
\hline & Drugs are safe & $13 \%$ & $24 \%$ & $45 \%$ & Cramér's V = \\
\hline & 0 & $28 \%$ & $49 \%$ & $70 \%$ & 0.205 \\
\hline
\end{tabular}

Source: Own research $(\mathrm{n}=2273)$

Empirical material analysis has shown that there is a statistically significant relation between truancy frequency results and perceiving drugs to be safe: Chi-Square $=94.642$; $\mathrm{p} \leq 0.001$; Cramér's $\mathrm{V}=0.205$, and similarly between the indicated intentional school absences and a liberal stand towards legalising marijuana: Chi-Square $=145.206 ; \mathrm{p} \leq 0.001 ;$ Cramér's V $=0.254$.

These data suggest that stands towards drugs may be distorted as a result of encountering pro-drug activities whilst truanting, observed amongst peers, drug initiations influenced by the per group resulting in a more liberal approach to drugs brought about by adolescents' personal experiences with such substances.

Summing up factors associated with the school environment conducive to drug use one has to concur that out of the discussed determinants, truancy is the variable with the strongest relationship with changing approach to drugs and as a result their use.

\section{Discussion}

Comparing data collected from amongst Podkarpackie youths with results of research carried out on Polish adolescents in 2015 within the scope of the European School Survey Project on Alcohol and Drug (ESPAD), the results of the present survey are far below the results obtained from second year secondary school students sampled from the general population, where nearly $40 \%$ pointed smoking tobacco, $96 \%$ reported drinking alcohol, $43 \%$ admitted smoking marijuana and between 2 and $17 \%$ of students said they used other substances, with actual percentages varying according to drug type (ESPAD Group, 2016). 
However, one should bear in mind that the ESPAD survey is carried out on a much more diverse group (specialised schools and basic vocational schools are also included in the sample), and thus data in this survey may differ from the ESPAD results (for example due to a different sample selection method). Furthermore, compared with other regions of Poland, Podkarpackie province youths are more attached to traditional values and are more religious. Researchers consider observing rules associated with following a given religion to be a protective factor against the use of drugs (Marsiglia et al., 2005; Yeung et al., 2009; Kovacs et al., 2011; Gomes et al., 2013; Jedynak \& Motyka, 2018).

A review of data obtained in other countries found similarities. Relationships between student status and drug use were identified in a survey carried out on Norwegian adolescents $(\mathrm{N}=7874)$. Statistically significant relationships were found between alcohol and drug use results and worse school performance (Heradstveit et al., 2017). Analogous results were achieved during research carried out on teenagers from Bosnia and Herzegovina $(\mathrm{N}=1032)$, where a negative correlation was found between smoking tobacco and alcohol consumption and school grades (Sekulic et al., 2012). Similar results were arrived at in a survey carried out on young Croatians $(\mathrm{N}=644)$, where data pointing worse school results were amongst students who consume alcohol (Devcic et al., 2018). International surveys carried out amongst students in Australia and their contemporaries in the United States showed that alcohol consumption frequency and the nature of behaviours associated with its consumption (especially drinking "into oblivion"), may effect school results and also increases the probability of a student drinking alcohol dropping out from a given school (Hemphill et al., 2014).

According to Public Opinion Research Centre (CBOS) surveys carried out on Poland in 2013 and 2016, lowest grade students were more likely to indicate use of intoxicants (22\% in that group). In 2016 only $13 \%$ of respondents (12\% in 2013) out of the top-grade students indicated using drugs. Furthermore, students with worse results were also more likely to admit drinking beer and vodka than top grade students (Malczewski, 2016).

According to Sime Devcic et al. (2018) school failures amongst children who consume alcohol may be explained by (at least) three mechanisms. The first, essentially considered to be physiological, suggest that early use of legal or illegal drugs may have a detrimental effect on brain development, cognitive abilities and in particular on memory, concentration and logical thinking, manifested in difficulties in assimilating knowledge and resulting in lower school grades. The second explanations (based on social psychology) suggests that individuals with poorer school results are more likely encounter "uncontrolled out-of-school circumstances" (for example when truanting), during which alcohol consumption is prevalent. And this behaviour furthers educational deficits. The third explanation, based on problem behaviour theory, suggest that alcohol consumption (or that of other drugs) appears in the so-called inappropriate behaviour tandem (Devcic et al., 2018). Causality was not identified the cited surveys; however, the results show strong links between drug use and school achievements.

Research on the impact of truancy on drug use was carried out, inter alia, by Kimberly L. 
Henry, who determined significant dependencies between results of the mutual impact between the two variables. Analysis of data collected from adolescents indicated that truancy in that group may be a very powerful predictor of drug use. Furthermore, according to research, not only can truancy be conducive to drug use, but also first drug contacts and later more frequent their use may cause intentional school absences (Henry, Thornberry, 2010).

In a survey carried out by researchers led by Richard Dembo, youths who play truant was also considered to be a social segment particularly at risk, within which various types of educational and family problems are observed alongside anti-social behaviours, such as drug use (Dembo et al., 2014). The relationships between truancy and drug use (tobacco, alcohol, illegal drugs) was also identified amongst Polish youths in a survey carried out between 2010 and 2014 by the Institute for integrated prevention $(\mathrm{N}=13,960)$. The report authors do not confirm the existence of a cause-and-effect relationship between the variables (that truancy is the cause of drug use), however the relationships between them were considered to be strong (Grzelak, 2015).

An important action conducive to reducing use of legal and illegal drugs is health promotion and schools becoming involved in preventative programmes within which youths promote education (McCrystal \& Winning 2009; Kumar et al., 2013; How, 2014). As was pointed out by Tracy Evans-Whipp et al. (2004), school policy within the scope of drug use prevention, as well as preventative programmes carried out in educational establishments vary, both in terms of reach as well as impact (Evans-Whipp et al., 2004). According to authors of school preventative policy reviews, sometimes in practice the programmes are ineffective (Ringwalt et al., 2009; Kumar, et al., 2013, NIK, 2013). Research carried out in Brazil showed that poor school prevention policy quality is, inter alia, caused by low abilities of those implementing the programmes, obliging teachers overburdened with tasks to carry out prevention activities, inadequate perception of the family usually blamed for drug use by the child and lack of cooperation between the school and the family, lacking experience in conducting activities associated with reducing negative consequences as well as insufficient cooperation between the school and other support institutions (Moreira et al., 2015). Data collected in Australian surveys indicate a lack of support for drug education in schools and implementing short-term programmes with low prevention and educational quality most secondary school's students showed little knowledge on legal and illegal drugs and the harm caused by their use (Midford, 2007). An inspection carried out in Polish schools between 2010 and 2012 by the Supreme Audit Office (NIK) found that the implemented preventative actions are having little effect. Low quality of implemented programmes, lack of action despite a drug problem being identified within a given school, teachers assigned to run addiction prevention lacking in relevant abilities and also insufficient pedagogical supervision over educational establishments were observed (NIK, 2013).

However, it should not be concluded that such actions are ineffective. School prevention programmes - if carried out correctly - may be a valuable drug policy tool used by schools for teenagers (Das et al., 2016). However, planned actions should be based on a reliable diagnosis of both the attitudes of youth to drugs as well as the scale of the phenomenon. The implemented actions should reflect actual and not only supposed needs. 


\section{Conclusion}

As is the case with many surveys, here also, the obtained answers constitute a basis for formulating further research problems which should be addressed.

Conclusions analogous to conclusions of research performed elsewhere in the world indicate the need to adopt an adequate drugs policy, where correctly planned preventative actions implemented by qualified staff may play a significant role. The obtained data point to similar causes for use of legal and illegal drugs by youths around the world:

- Drug use amongst students increases with age of respondents.

- Students achieving higher grades use cigarettes, alcohol and drugs significantly less frequently than students who achieve lower grades.

- Students declaring the intention to remain in education are less likely to use drugs than students without such aspirations.

- Youths who play truant are more likely to use various drugs than youths who deny intentional school absences.

In this research, authors did not undertake to determine relationships between the school's drug policy and drug use responses. Nonetheless such actions are planned for future research. However, the authors are hopeful that the presented results will contribute to developing effective prevention strategies, which will find application in many countries and lead to a reduction in youths using drugs. 


\section{References}

Bahr, S. J., Hoffmann, J. P., \& Yang, X. (2005). Parental and Peer Influences on the Risk of Adolescent Drug Use. The Journal of Primary Prevention, 26(6), 529-551.

Bandura, A. (1977). Self-efficacy. Toward a Unifying Theory of Behavioral Change. Psychology Review, 85(2), 191-215.

Barnard, M. (2005). Drugs in the Family: The Impact on Parents and Siblings. York: Joseph Rowntree Foundation.

Brook, S. J., Brook, W. D., Gordon, S. A., Whiteman, M., \& Cohen, P. (1990). The Psychosocial Etiology of Adolescent Drug Use: A Family Interactional Approach. Genetic, Social and General Psychology Monographs, 116(2), 111-267.

Das, J. K., Salam, R. A., Arshad, A., Finkelstein, Y., \& Bhutta, Z. A. (2016). Interventions for Adolescent Substance Abuse: An Overview of Systematic Reviews. Journal of Adolescent Health, 59(4, Supplement), S61-S75.

Devcic, S., Sekulic, D., Ban, D., Kutlesa, Z., Rodek, J., \& Sajber, D. (2018). Evidencing Protective and Risk Factors for Harmful Alcohol Drinking in Adolescence: A Prospective Analysis of Sport-Participation and Scholastic-Achievement in Older Adolescents from Croatia. International Journal of Environmental Research and Public Health, 15(5), 986. doi: 10.3390/ijerph15050986

Dembo, R., Briones-Robinson, R., Wareham, J., Schmeidler, J., Winters, K. C., Barrett, K., Ungaro, R., Karas, L. M., \& Belenko, S. (2014). Impact of Brief Intervention Services on Drug Using Truant Youth Arrest Charges over Time. Journal of Child and Adolescent Substance Abuse, 23(6), 375-388.

ESPAD Group. (2016). ESPAD Report 2015: Results from the European School Survey Project on Alcohol and Other Drugs. Luxembourg: Publications Office of the European Union.

Evans-Whipp, T., Beyers, J. M., Lloyd, S., Lafazia, A. N., Toumbourou, J. W., Arthur, M. W., \& Catalano, R. F. (2004). A review of school drug policies and their impact on youth substance use. Health Promotion International, 19(2), 227-234.

Gomes, F. C., Andrade, A. G., Izbicki, R., Moreira-Almeida, A., \& Oliveira, L. G. (2013). Religion as a protective factor against drug use among brazilian university students: a national survey. Brazilian Journal of Psychiatry, 35(1), 29-37.

Grzelak, Sz. (2015). Vademecum skutecznej profilaktyki problemów młodzieży. Przewodnik dla samorzadowców i praktyków oparty na wynikach badań naukowych. Warszawa: Ośrodek Rozwoju Edukacji.

Hemphill, S. A., Heerde, J. A., Scholes-Balog, K. E., Herrenkohl, T. I., Toumbourou, J. W., \& Catalano, R. F. (2014). Effects of early adolescent alcohol use on mid-adolescent school performance and connection: a longitudinal study of students in Victoria, Australia and Washington State, United States. The Journal of School Health, 84(11), 706-715. 
Henry, K. L., \& Thornberry, T. P. (2010). Truancy and Escalation of Substance Use During Adolescence. Journal of Studies on Alcohol and Drugs, 71(1), 115-124.

Heradstveit, O., Skogen, J. C., Hetland, J., \& Hysing, M. (2017). Alcohol and Illicit Drug Use Are Important Factors for School-Related Problems among Adolescents. Frontiers in Psychology, 8, 1023. doi: 10.3389/fpsyg.2017.01023

How, T. B. (2014). Drug education in schools: laying the foundation for drug abuse prevention. International Journal of Prevention and Treatment of Substance Use Disorders, 1(2), 98-107.

Jedynak, W., \& Motyka, M. A. (2018). Autodeklaracja religijności i związki tej zmiennej ze wskazaniami używania środków psychoaktywnych: dane z badań $(\mathrm{n}=2273)$. Roczniki Teologiczne, 65(10), 139-161.

Kovacs, E., Piko, B. F., \& Fitzpatrick, K. M. (2011). Religiosity as a Protective Factor Against Substance Use Among Hungarian High School Students. Substance Use \& Misuse, 46(10), 1346-1357.

Kumar, R., O'Malley, P. M., Johnston, L. D., \& Laetz, V. B. (2013). Alcohol, tobacco, and other drug use prevention programs in U.S. schools: a descriptive summary. Prevention Science, 14(6), 581-592.

Lee, G., Akers, R. L., \& Borg, M. (2004). Social learning and structural factors in adolescent substance use. Western Criminology Review, 5, 17-34.

Malczewski, A. (2016). Młodzież a substancje psychoaktywne. In CBOS. Młodzież 2016. (pp. 200-225.). Warszawa: KBPN.

Marsiglia, F. F., Kulis, S., Nieri, T., \& Parsai, M. (2005). God forbid! Substance use among religious and non-religious youth. The American Journal of Orthopsychiatry, 75(4), 585-598.

McCrystal, P., \& Winning, K. (2009). Drugs Education and Prevention for School-aged Young People. Child Care in Practice, 15(4), 341-352.

Midford, R. (2007). Is Australia 'fair dinkum' about drug education in schools? Drug and Alcohol Review, 26(4), 421-427.

Moreira, A., Vóvio, C. L., \& De Micheli, D. (2015). Drug abuse prevention in school: challenges and possibilities for the role of the educator. Educação e Pesquisa, 41(1), 119-135.

NIK. (2013). Profilaktyka narkomanii w szkołach. Informacja o wynikach kontroli. Retrieved on August 14, 2019, from https://www.nik.gov.pl/plik/id,5334,vp,6917.pdf.

Ringwalt, Ch., Vincus, A. A., Hanley, S., Ennett, S. T., Bowling, J. M., \& Rohrbach, L. A. (2009). The Prevalence of Evidence-Based Drug Use Prevention Curricula in U.S. Middle Schools in 2005. Prevention Science, 10(1), 33-40.

Sadowski, A. (2013). Wschodnie województwa Rzeczypospolitej - uwarunkowania konstruowania kapitału pogranicza. Konteksty Społeczne, 2, 8-17. 
Sekulic, D., Ostojic, M., Ostojic, Z., Hajdarevic, B., \& Ostojic, L. (2012). Substance abuse prevalence and its relation to scholastic achievement and sport factors: an analysis among adolescents of the Herzegovina-Neretva Canton in Bosnia and Herzegovina. BMC Public Health, 12, 274. doi: 10.1186/1471-2458-12-274

Véronneau, M. H., Trempe, S. C., \& Paiva, A. O. (2014). Risk and protection factors in the peer context: how do other children contribute to the psychosocial adjustment of the adolescent? Ciência \& Saúde Coletiva, 19(3), 695-705.

Walker, T. (2016). Educators Look to Parents and Communities to Help Reduce Student Stress. NEA Today. Retrieved on August 14, 2019, from http://neatoday.org/2016/09/16/reducing-student-stress/.

White, J. (2006). The Aims of School Education. Retrieved on August 14, 2019, from https://www.researchgate.net/publication/228734545_The_Aims_of_School_Education.

Williams, J., Davis, L., Johnson, S., Williams, T., Saunders, J., \& Von Nebbitt, E. (2007). Substance Use and Academic Performance among African American High School Students. Social Work Research, 31(3), 151-161.

Yeung, J. W., Chan, Y. C., \& Lee, B. L. (2009). Youth Religiosity and Substance Use: A Meta-Analysis from 1995 to 2007. Psychological Reports 105(1), 255-266. 